\title{
PENGARUH PENAMBAHAN FLY ASH DAN SILICA FUME TERHADAP DAYA TAHAN PENETRASI AIR BETON NORMAL
}

\author{
THE EFFECT OF FLY ASH AND SILICA FUME ADDITIONS ON WATER \\ PERMEABILITY ASPECT OF NORMAL CONCRETE
}

\author{
Ariyadi Basuki \\ Balai Besar Bahan dan Barang Teknik, Jl. Sangkuriang No. 14 Bandung 40135 \\ Email: ariyadib@gmail.com
}

Diterima: 22 April 2015

Direvisi: 21 Mei 2015

Disetujui:19 Juni 2015

\begin{abstract}
ABSTRAK
Pada penelitian ini dilakukan serangkaian pengujian untuk mengetahui karakteristik komposisi rencana beton dengan mutu fc $30 \mathrm{MPa}$ (normal/kontrol) yang dipadukan dengan aditif fly ash 10-15\% dan Silica Fume 5\% dari berat semen. Variasi campuran menggunakan tiga tipe admixtures yang berbeda yaitu tipe F+tipe G (trial mix 1) dan tipe D+tipe G (Trial mix 2). Proses dilanjutkan dengan pembuatan sampel uji silinder berukuran $15 \mathrm{~cm}$ x $30 \mathrm{~cm}$ (karakteristik kuat tekan), sampel uji prisma berukuran $20 \mathrm{~cm}$ x $20 \mathrm{~cm}$ x $12 \mathrm{~cm}$ (karakteristik permeabilitas, setting time). Pengamatan dilakukan untuk melihat karakteristik beton fc 30 MPa dengan penambahan aditif fly ash ataupun silica fume, dibandingkan dengan beton normal sebagai acuan, serta aplikasinya dalam lingkungan panas. Hasil kuat tekan memperlihatkan bahwa campuran dengan menggunakan admixtures tipe $\mathrm{D}+$ tipe $\mathrm{G}$ memiliki nilai kuat tekan rata-rata diatas kriteria rencana fc $30 \mathrm{MPa}$. Penambahan fly ash pada campuran beton akan menaikkan nilai kuat tekan sebesar 1,1\% dibandingkan beton normal dengan nilai rasio air-semen nya mengecil menjadi 0,3-0,4 karena pengurangan air. Campuran dengan penambahan aditif fly ash atau silica fume menunjukkan nilai penetrasi yang relatif sama bila dibandingkan campuran beton normal, hal ini mengindikasikan produk beton yang terbentuk memiliki kepadatan yang relatif sama dan dapat dikatakan memiliki tingkat durabilitas yang cukup baik (nilai penetrasi $<5 \mathrm{~cm}$ ).
\end{abstract}

Kata kunci: penetrasi air, admixtures, pemanfaatan silica fume, fly ash

\section{ABSTRACT}

In this research a series of tests to determine the characteristics of the composition of concrete with grade $f c$ $30 \mathrm{MPa}$ (normal/control) combined with fly ash additive (10-15\%) or silica fume (5\%) of cement weight was conducted. Variation of mixtures are using three different types of admixtures such as type F combined with type $G$ (in trial mix 1) and type D combined with type $G$ (in trial mix 2). The process was continued with the making of cylindrical samples of $15 \mathrm{~cm}$ diameter by $30 \mathrm{~cm}$ height (compressive strength characteristic), prism samples with the size of $20 \mathrm{~cm} \times 20 \mathrm{~cm} \times 12 \mathrm{~cm}$ (permeability characteristic). Observations were made to know the characteristics of the concrete grade $30 \mathrm{MPa}$ with the addition of additives fly ash or silica fume, compared with normal concrete as a reference, and their application in hot environment. Result of compressive strength value show that mixture with admixtures type $D$ combined with type $G$ has the value of average compressive strength above grade $30 \mathrm{MPa}$ (plan criteria). The addition of fly ash in concrete mix will increase the compressive strength value up to $1.1 \%$ compared to the normal value with water-cement ratio decreases to 0.3 until 0.4 due to the reduction of water content. Mixtures with addition of fly ash or silica fume shows the water penetration value relatively equal compared to normal mixtures, this indicated that concrete products have relatively the same density and can be said to have a fairly good level of durability (penetration value $<5 \mathrm{~cm}$ ).

Keywords: water penetration, admixtures, silica fume utilization, fly ash

\section{PENDAHULUAN}

Aspek keawetan (durability) pada material beton memegang peranan dalam penentuan lama usia layan suatu konstruksi beton. Kerusakan lapisan permukaan atau kegagalan struktururural menunjukkan adanya degradasi dari material beton akibat pengaruh cuaca, efek lingkungan kimia, atau efek benturan/ tekanan. 
Konstruksi bangunan yang berada di lingkungan basah, lembab dan terendam air mengharuskan kriteria beton yang kedap air. Hal ini akan menjamin tidak terjadinya resiko korosi pada tulangan baja dalam beton. Kerusakan pada permukaan beton seperti retakan, pengelupasan lapisan selimut beton (spalling, delamination), pada umumnya diawali dengan terjadinya korosi pada tulangan baja dalam beton.

Dari beberapa penelitian, diketahui bahwa penambahan bahan-bahan aditif yang bersifat pozzolan pada beton, seperti silica fume dan fly ash, akan mampu meningkatkan sifat kekedapan terhadap penetrasi air. Penggunaan fly ash akan mampu memodifikasi karakteristik dari beton segar maupun beton keras melalui perbaikan tingkat kelecakannya, kekuatan dan ketahanan aus/ abrasi [1]. Fly ash sebagai bahan pengganti semen mampu meningkatkan kuat tekan dan modulus elastisitas dari beton serta tingkat porositas berkurang pada usia pengamatan hingga 130 hari [2]. Karakteristik dari fly ash berkontribusi pada peningkatan kekuatan tekan dan keawetan ketika digunakan bersama-sama dengan semen Portland [3]. Penggunaan silica fume pada self compacting concrete menunjukkan nilai kekuatan tekan yang lebih baik dibandingkan dengan menggunakan fly ash [4].

Silica fume merupakan produk samping (by product) dari silicon metal atau ferro-silicon alloys. Penggunaannya dalam campuran beton mampu meningkatkan manfaat lebih, hal ini disebabkan karena secara sifat fisika dan kimia, aditif ini bersifat pozzolan reaktif. Beton yang mengandung silica fume dapat memiliki kuat tekan yang tinggi dan sangat awet (durable). Silica fume mengandung unsur utama yaitu silicon dioxide $\left(\mathrm{SiO}_{2}\right)$, partikel individunya sangat kecil, kurang lebih 1/100 kali dari ukuran partikel semen rata-rata. Karena kehalusannya tersebut, area permukaan lebih luas dan kandungan $\mathrm{SiO}_{2}$ yang tinggi, maka bersifat pozzolan reaktif. Beton dengan kandungan silica fume serta kadar air rendah, tahan terhadap penetrasi ion klorida, sehingga mampu mengurangi resiko korosi pada tulangan baja dalam beton.

Fly ash merupakan residu yang dihasilkan dari pembakaran batu bara yang kemudian terbawa oleh gas buang.

Dalam penelitian ini akan diamati produk beton yang menggunakan dua macam bahan aditif, yaitu: fly ash dan silica fume yang dipadukan dengan admixture super plasticizer dan retarder yang akan disimulasikan pada lingkungan yang berisiko terintrusi oleh air (simulasi dilaboratorium). Penambahan silica fume ataupun fly ash tersebut untuk meningkatkan karakteristik permeabilitas (daya tahan terhadap intrusi air pada beton), juga guna memastikan karakteristik dari beton segar tetap memiliki kelecakan yang baik serta memiliki waktu pengerasan yang relatif lebih lama agar pada saat pengecoran di area yang luas. Beton segar dapat menyatu dengan baik sehingga tetap didapat kondisi yang homogen.

Hasil yang ingin dicapai dari penelitian ini, yaitu tercapainya nilai kuat tekan rencana beton baik produk beton acuan maupun beton dengan penambahan aditif dan admixture pada kuat tekan rencana fc 30MPa, tercapai nilai penetrasi/intrusi air yang rendah (sesuai standar DIN 1045, dibawah $5 \mathrm{~cm}$ ) serta tetap mudah diaplikasikan dilapangan (tingkat kelecakan diatas $8 \mathrm{~cm}$ dan waktu pengerasan beton diatas 5 jam).

\section{BAHAN DAN METODE}

\section{Bahan}

Penelitian ini menggunakan bahan-bahan: semen, agregat, fly ash dan silica fume, admixtures (bahan-bahan kimia aditif). Bahanbahan ini dicampur dalam komposisi yang direncanakan.

\section{Semen}

Produk semen PCC (Portland Composite Cement) yang proses produksinya lebih ramah lingkungan serta diklaim memiliki karakteristik mekanik dan keawetan yang lebih baik dibanding produk semen OPC, sesuai dengan SNI 170642004. Semen Portland Campur adalah Bahan pengikat hidrolisis hasil penggilingan bersama sama terak (clinker) semen portland dan gibs dengan satu atau lebih bahan anorganik, atau hasil pencampuran antara bubuk semen portland dengan bubuk bahan anorganik lain. Bahan anorganik tersebut antara lain terak tanur tinggi (blast furnace slag), pozzolan, senyawa silika, batu kapur, dengan kadar total bahan anorganik 6 -35\% dari massa semen portland composite. Menurut Standard Eropa EN 197-1 Portland Composite Cement atau Semen Portland Campur dibagi menjadi 2 tipe berdasarkan jumlah aditif material aktif, yaitu: Tipe II/A-M yang 
mengandung 6-20\% aditif dan Tipe II/B-M yang mengandung $21-35 \%$ aditif. Dalam penelitian ini digunakan semen PCC ex Gresik.

\section{Agregat}

Agregat yang digunakan dalam penelitian ini ada dua yaitu: (1) agregat halus dengan bentuk partikel pasir yang bundar dan tekstur yang halus. Pasir dengan modulus kehalusan dalam kisaran 3 akan memberikan kelecakan (workability) dan kekuatan tekan produk beton yang baik $[6,10]$. Jumlah pasir yang melewati saringan no. 50 dan no. 100 haruslah rendah, tapi tetap sesuai dengan persyaratan ASTM C33 serta kandungan mica/clay harus ditiadakan. Dalam penelitian ini digunakan pasir ex Lumajang. (2) agregat kasar dengan jumlah maksimum kerikil harus dibuat minimum pada ukuran $12,7 \mathrm{~mm}$ atau 9,5 mm, maksimum pada ukuran $19 \mathrm{~mm}$ dan 25,4 $\mathrm{mm}$ [11]. Batu pecah akan menghasilkan kekuatan yang lebih tinggi dibanding batu bundar, hal ini karena ikatan mekanis yang lebih besar akan dihasilkan bila menggunakan partikel yang angular (bersudut), akan tetapi bentuk bersudut yang pipih harus dihindari karena bertendensi meningkatkan jumlah air serta mengurangi kelecakan beton. Agregat yang ideal, haruslah bersih, kubikal, bersudut, $100 \%$ batuan pecah yang minim bentuk partikel pipih dan memanjang [6], dalam penelitian ini digunakan batu pecah 9,5-19,5 mm, 20-30 mm ex Mojokerto.

\section{Fly Ash dan Silica Fume}

Sesuai dengan ketentuan dalam ASTM C1240, silica fume dipersyaratkan memiliki kandungan $\mathrm{SiO}_{2}$ minimal 85\%, kadar kelembaban maksimum 3\% dan abu pijar (loss of ignition) maksimum 6\%. Sedangkan sesuai dengan ASTM C618, fly ash terdapat 3 klasifikasi yaitu: (1) class N (pozzolan alami), (2) class $\mathrm{F}$ (mengandung karakteristik pozzolan), dan (3) Class C (Pozzolan + karakteristik cementitious). Dalam penelitian ini digunakan silica fume 5\% dan fly ash ex Paiton $10 \%$ atau $15 \%$.

\section{Admixtures Tipe D, F dan G}

Dalam penelitian ini digunakan admixtures untuk menghasilkan beton dengan karakteristik antara lain: mudah mengalir dan tahan lama, dapat memberikan pengurangan air dalam jumlah besar (hingga 30\%), pemadatan beton dengan sendirinya (self-compacting concrete/SCC), beton berkekuatan tinggi, serta beton kedap air (watertight concrete), memperpanjang waktu pengikatan di cuaca yang panas, meningkatkan kelecakan beton tanpa meningkatkan jumlah air, meningkatkan perkembangan kekuatan beton, mengurangi resiko susut dan rangkak, mengontrol kehilangan slump lebih lama, serta menjadikan permukaan beton yang lebih rata/bagus. Dalam penelitian ini digunakan admixtures: tipe D ex SIKA Visco Crete $3115 \mathrm{~N}$, tipe $\mathrm{F}$ ex SIKAment LN, dan tipe G, ex SIKA Plastiment AR-07.

\section{Metode}

Dalam penelitian ini, beton dibuat dari dua macam komposisi campuran bahan-bahan (mix design), dan dinamai trial-1 dan trial-2. Hasil beton diuji kekuatan mekanik dan keawetannya.

\section{Mix Design}

Pengujian material agregat dilakukan untuk mengetahui sifat fisiknya yang harus mengikuti SNI atau ASTM. Komposisi rencana beton dirancang dengan target mutu fc $30 \mathrm{MPa}$ (beton normal/ acuan), serta variasi beton dengan penambahan fly ash $10 \%$ atau $15 \%$ dan silica fume $5 \%$.

Campuran trial-1 dibuat dengan admixtures tipe $\mathrm{F}$ dan $\mathrm{G}$, sedangkan trial-2 dibuat dengan admixtures tipe D dan G. Sifat kelecakan beton diharapkan sesuai dengan yang direncanakan, yaitu nilai slump pada kisaran 10-18 $\mathrm{cm}$. Hasil rancangan dibuat sampel uji: beton silender dan beton prisma. Uji sifat beton mencakup kuat tekan, sifat kekedapan terhadap air,dan lama pengerasan beton segar (setting time). Kombinasi campuran adalah seperti berikut (lihat Tabel 1 dan Tabel 2).

a) Beton Normal fc $30 \mathrm{MPa}$, (acuan, tanpa fly ash dan silica fume), semen Tipe PCC, admixtures tipe $\mathrm{F}$ dan tipe $\mathrm{G}$ (trial 1), dan admixtures tipe $\mathrm{D}$ dan tipe $\mathrm{G}$ (trial 2)

b) Beton fc $30 \mathrm{MPa}+$ Fly Ash 10\%, admixtures tipe $\mathrm{F}$ dan tipe $\mathrm{G}$ (trial 1), dan admixtures tipe $\mathrm{D}$ dan tipe $\mathrm{G}$ (trial 2)

c) Beton fc $30 \mathrm{MPa}+$ Fly Ash 15\%, admixtures tipe F dan tipe G (trial 1), dan admixtures tipe D dan tipe $\mathrm{G}$ (trial 2)

d) Beton fc $30 \mathrm{MPa}+$ Silica Fume 5\%, admixtures tipe $\mathrm{F}$ dan tipe $\mathrm{G}$ (trial 1), dan admixtures tipe $\mathrm{D}$ dan tipe $\mathrm{G}$ (trial 2)

Percobaan dilakukan di lokasi batching plant dan suhu lingkungan $27-33^{\circ} \mathrm{C}$. 
Tabel 1. Komposisi Rencana Trial Mix 1

\begin{tabular}{|c|c|c|c|c|c|c|}
\hline \multirow{2}{*}{ No } & \multirow{2}{*}{$\begin{array}{l}\text { Komposisi } \\
\text { Trial Mix } 1\end{array}$} & \multicolumn{4}{|c|}{ Tipe Campuran, Jumlah } & \multirow{2}{*}{ Keterangan } \\
\hline & & Normal & + FA $10 \%$ & + FA $15 \%$ & +SF 5\% & \\
\hline 1 & Semen $\left(\mathrm{kg} / \mathrm{m}^{3}\right)$ & 367 & 354 & 342 & 349 & Tipe 1 ex Gresik \\
\hline $2 a$ & Fly Ash $\left(\mathrm{kg} / \mathrm{m}^{3}\right)$ & 0 & 36 & 52 & & $\begin{array}{l}\text { ex Paiton BJ SSD } \\
2,8\end{array}$ \\
\hline $2 b$ & $\begin{array}{l}\text { Silica Fume } \\
\left(\mathrm{kg} / \mathrm{m}^{3}\right)\end{array}$ & & & & 18 & $\begin{array}{l}\text { ex SIKA, BJ SSD } \\
2,8\end{array}$ \\
\hline 3 & $\operatorname{Pasir}\left(\mathrm{kg} / \mathrm{m}^{3}\right)$ & 802,7 & 758,1 & 761,3 & 781,6 & $\begin{array}{l}\text { Ex Lumajang, BJ } \\
\text { SSD : } 2,7\end{array}$ \\
\hline 4 & $\begin{array}{l}\text { Batu pecah 10-20 } \\
\mathrm{mm}\left(\mathrm{kg} / \mathrm{m}^{3}\right)\end{array}$ & 792 & 793 & 791 & 802 & $\begin{array}{l}\text { Ex Mojokerto, BJ } \\
\text { SSD : } 2,59\end{array}$ \\
\hline 5 & $\begin{array}{l}\text { Batu pecah 20-30 } \\
\mathrm{mm}\left(\mathrm{kg} / \mathrm{m}^{3}\right)\end{array}$ & 264 & 264 & 264 & 267 & $\begin{array}{l}\text { Ex Mojokerto, BJ } \\
\text { SSD : } 2,62\end{array}$ \\
\hline 6 & $\begin{array}{l}\text { Admixture Tipe } \\
\text { G, ASTM C494 } \\
\left(\mathrm{L} / \mathrm{m}^{3}\right)\end{array}$ & 2,18 & 2,31 & 2,34 & 2,34 & $\begin{array}{l}\text { SIKA Plastiment } \\
\text { AR-07 (Retarder) }\end{array}$ \\
\hline 7 & $\begin{array}{l}\text { Admixture Tipe F, } \\
\text { ASTM C494 } \\
\left(\mathrm{L} / \mathrm{m}^{3}\right)\end{array}$ & 2,3 & 2 & 1,5 & 1,5 & $\begin{array}{l}\text { SIKAment LN } \\
\text { (Superplasticizer) }\end{array}$ \\
\hline 8 & Air $\left(\mathrm{kg} / \mathrm{m}^{3}\right)$ & 175 & 195 & 190 & 180 & \\
\hline 9 & Slump $(\mathrm{cm})$ & 14 & 16 & 18 & 18 & Sesuai rencana \\
\hline
\end{tabular}

Tabel 2. Komposisi Rencana Trial Mix 2

\begin{tabular}{|c|c|c|c|c|c|c|}
\hline \multirow{2}{*}{ No } & \multirow{2}{*}{$\begin{array}{l}\text { Komposisi } \\
\text { Trial Mix } 2\end{array}$} & \multicolumn{4}{|c|}{ Tipe Campuran, Jumlah } & \multirow{2}{*}{ Keterangan } \\
\hline & & Normal & + FA $10 \%$ & + FA $15 \%$ & + SF $5 \%$ & \\
\hline 1 & Semen $\left(\mathrm{kg} / \mathrm{m}^{3}\right)$ & 395 & 375 & 360 & 375 & Tipe 1 ex Gresik \\
\hline $2 a$ & Fly Ash $\left(\mathrm{kg} / \mathrm{m}^{3}\right)$ & 0 & 42 & 62 & & $\begin{array}{c}\text { ex Paiton BJ SSD : } \\
2,8\end{array}$ \\
\hline $2 b$ & Silica Fume $\left(\mathrm{kg} / \mathrm{m}^{3}\right)$ & & & & 20 & $\begin{array}{c}\text { ex SIKA, BJ SSD : } \\
2,8\end{array}$ \\
\hline 3 & Pasir $\left(\mathrm{kg} / \mathrm{m}^{3}\right)$ & 805,1 & 769 & 766 & 793 & $\begin{array}{l}\text { Ex Lumajang, BJ } \\
\text { SSD : } 2,7\end{array}$ \\
\hline 4 & $\begin{array}{l}\text { Batu pecah 10-20 mm } \\
\left(\mathrm{kg} / \mathrm{m}^{3}\right)\end{array}$ & 789 & 790 & 787 & 788 & $\begin{array}{l}\text { Ex Mojokerto, BJ } \\
\text { SSD : } 2,59\end{array}$ \\
\hline 5 & $\begin{array}{l}\text { Batu pecah 20-30 mm } \\
\left(\mathrm{kg} / \mathrm{m}^{3}\right)\end{array}$ & 263 & 263 & 262 & 263 & $\begin{array}{l}\text { Ex Mojokerto, BJ } \\
\text { SSD : } 2,62\end{array}$ \\
\hline 6 & $\begin{array}{l}\text { Admixture Tipe G, } \\
\text { ASTM C494 (L/m³) }\end{array}$ & 2,01 & 2,12 & 2,15 & 2,01 & $\begin{array}{c}\text { SIKA Plastiment } \\
\text { AR-07 (Retarder) } \\
\text { SIKA }\end{array}$ \\
\hline 7 & $\begin{array}{l}\text { Admixture Tipe D, } \\
\text { ASTM C494 }\left(\mathrm{L} / \mathrm{m}^{3}\right)\end{array}$ & 2 & 1,77 & 1,7 & 1,77 & $\begin{array}{c}\text { VISCOCRETE } \\
\text { 3115N } \\
\text { (Superplasticizer + } \\
\text { Retarder) }\end{array}$ \\
\hline 8 & $\operatorname{Air}\left(\mathrm{kg} / \mathrm{m}^{3}\right)$ & 186 & 154 & 113 & 154 & \\
\hline 9 & Slump $(\mathrm{cm})$ & 16 & 18 & 18 & 18 & $\begin{array}{c}\text { Slump Rencana } \\
10 \pm 2 \mathrm{~cm}\end{array}$ \\
\hline
\end{tabular}

Pengujian Mekanik dan Durabilitas

Pengujian kuat tekan silinder beton (ASTM C39) dilakukan dengan menggunakan cetakan silinder (diameter $15 \mathrm{~cm}$ dan tinggi 30 $\mathrm{cm}$ ). Sedangkan cetakan prisma (dasar 20x20 $\mathrm{cm}^{2}$ dan tinggi $12 \mathrm{~cm}$ ) digunakan untuk pengujian kedap air (DIN 1048) dan uji waktu pengikatan (ASTM C403). 
Pengujian menggunakan mesin kuat tekan kapasitas 200 ton, mesin kedap air dengan tekanan rata-rata 5 bar, ruang Curing/Moist Room, mixer, alat uji waktu pengikatan (setting time), molen+batching plant PT. AJG.

\section{HASIL DAN PEMBAHASAN}

Hasil trial pertama (Tabel 3) menunjukkan bahwa rata-rata waktu pengikatan diatas 5 jam untuk beton normal, sedangkan penambahan admixtures mampu memperpanjang waktu pengikatan hingga 6-7 jam.

Sifat kedap pada produk beton ini masih belum memenuhi persyaratan $(<5 \mathrm{~cm})$, hal ini diperkirakan karena seiring dengan penggunaan admixture, tidak disertai dengan pengurangan jumlah air (seperti terlihat pada Tabel 1, butir 8): beton tanpa admixture memiliki jumlah air 175 $\mathrm{kg} / \mathrm{m}^{3}$, dan seharusnya beton dengan admixture jumlah airnya kurang dari $175 \mathrm{~kg} / \mathrm{m}^{3}$ ). Beton bentuk akhir diperkirakan berpori banyak.

Hasil percobaan trial kedua memperlihatkan bahwa rata-rata waktu pengikatan 7 jam untuk beton normal, dan penambahan admixtures mampu memperpanjang waktu pengikatan hingga 7-10 jam. Sifat kedap pada produk beton ini dapat memenuhi persyaratan $(<$ $5 \mathrm{~cm}$ ). Hal ini mungkin dihasilkan akibat pengurangan jumlah air $17-40 \%$ dari kondisi awal (lihat Tabel 2, butir 8): beton tanpa admixture dengan jumlah air $186 \mathrm{~kg} / \mathrm{m}^{3}$, sedangkan beton dengan admixture jumlah airnya kurang dari $186 \mathrm{~kg} / \mathrm{m}^{3}$. Jadi beton akhir diperkirakan cukup padat.

Penggunaan aditif silica fume ataupun fly ash dapat mereduksi jumlah semen 5-9\% dibandingkan dengan beton normal. Hasil kekuatan tekan produk beton pada usia 28 hari, rata-rata menunjukkan nilai diatas kuat tekan rencana (> $30 \mathrm{MPa}$ ). Hasil pengujian trial kedua terlihat pada Tabel 4.

Perbandingan hasil-hasil penting antara trial 1 dan trial 2 disajikan pada Gambar 1, Gambar 2, dan Gambar 3 berturut-turut untuk sifat kelecakan, perbadingan air semen dan nilai penetrasi air. Kondisi kelecakan trial 2 lebih seragam daripada hasil trial 1. Ketercapaian nilai penetrasi air (Gambar 3) dapat diperoleh pada trial 2 dengan mengatur perbandingan air terhadap semen (Gambar 2).

Tabel 3. Hasil Trial Mix Pertama

\begin{tabular}{llcccc}
\hline \multirow{2}{*}{ No. } & \multirow{2}{*}{ Parameter Uji } & Normal & + FA 10\% & + FA 15\% & +SF 5\% \\
\cline { 3 - 6 } & & $3: 22: 00$ & $3: 25: 00$ & $5: 07: 00$ & $5: 12: 00$ \\
1a & Setting Awal & $5: 36: 00$ & $5: 54: 00$ & $6: 24: 00$ & $6: 55: 00$ \\
1b & Setting Akhir & 5,5 & 6 & 12 & 7,2 \\
\hline
\end{tabular}

Tabel 4. Hasil Trial Mix Kedua

\begin{tabular}{|c|c|c|c|c|c|c|}
\hline \multirow[b]{2}{*}{ No. } & \multirow[b]{2}{*}{ Parameter Uji } & \multicolumn{4}{|c|}{ Nilai Hasil Uji (rata-rata) } & \multirow[b]{2}{*}{ Keterangan } \\
\hline & & Normal & $\begin{array}{l}+\mathrm{FA} \\
10 \%\end{array}$ & $\begin{array}{l}+\mathrm{FA} \\
15 \%\end{array}$ & $\begin{array}{l}+\mathrm{SF} \\
5 \%\end{array}$ & \\
\hline $1 \mathrm{a}$ & Setting Awal & $6: 00: 00$ & 6:06:00 & 7:05:00 & 8:30:00 & \\
\hline $1 b$ & Setting Akhir & $7: 15: 00$ & 7:30:00 & 8:40:00 & 9:55:00 & \\
\hline 2 & Penetrasi Air (cm) & 1,5 & 2,1 & 2,8 & 1,8 & $\begin{array}{c}\text { Persyaratan DIN } \\
1045,<5 \mathrm{~cm}\end{array}$ \\
\hline 3 & $\begin{array}{l}\text { Kuat tekan } 28 \text { hari } \\
\text { (MPa) }\end{array}$ & 62,94 & 69,49 & 65,74 & 61,90 & \\
\hline
\end{tabular}




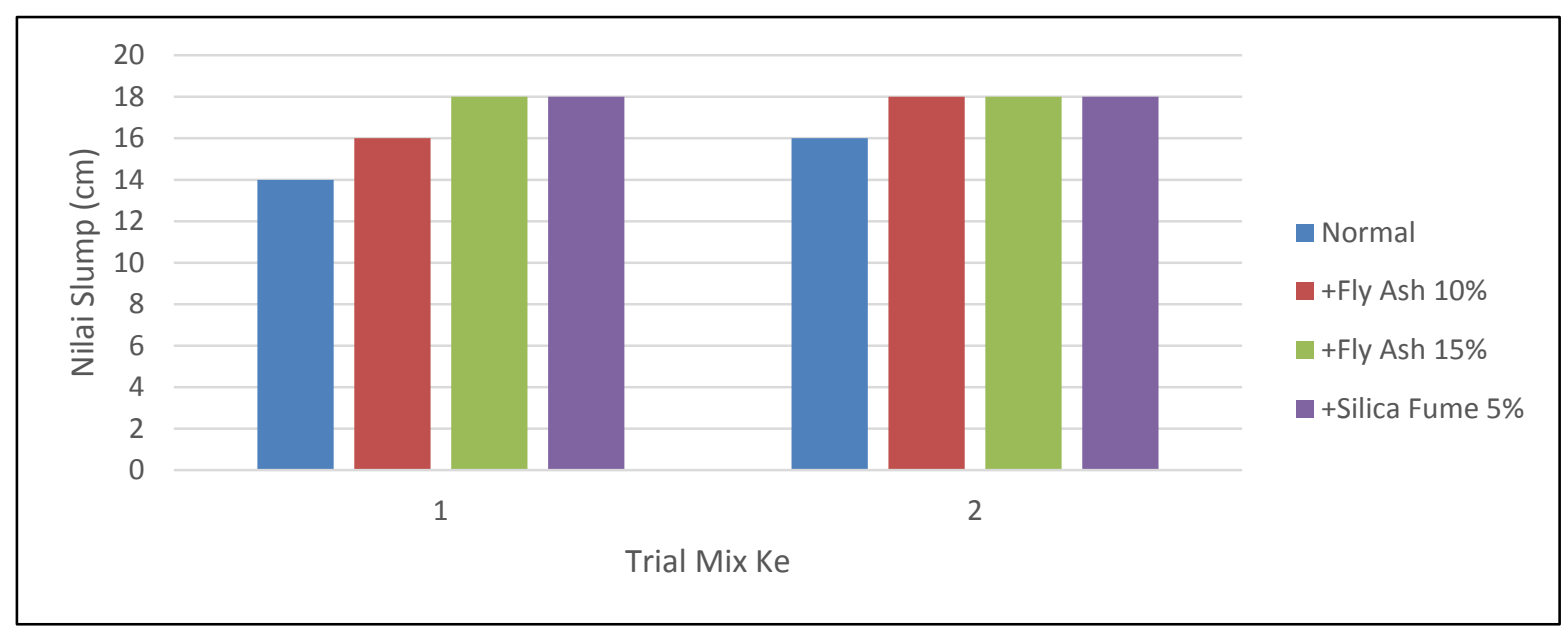

Gambar 1. Kondisi Kelecakan Campuran

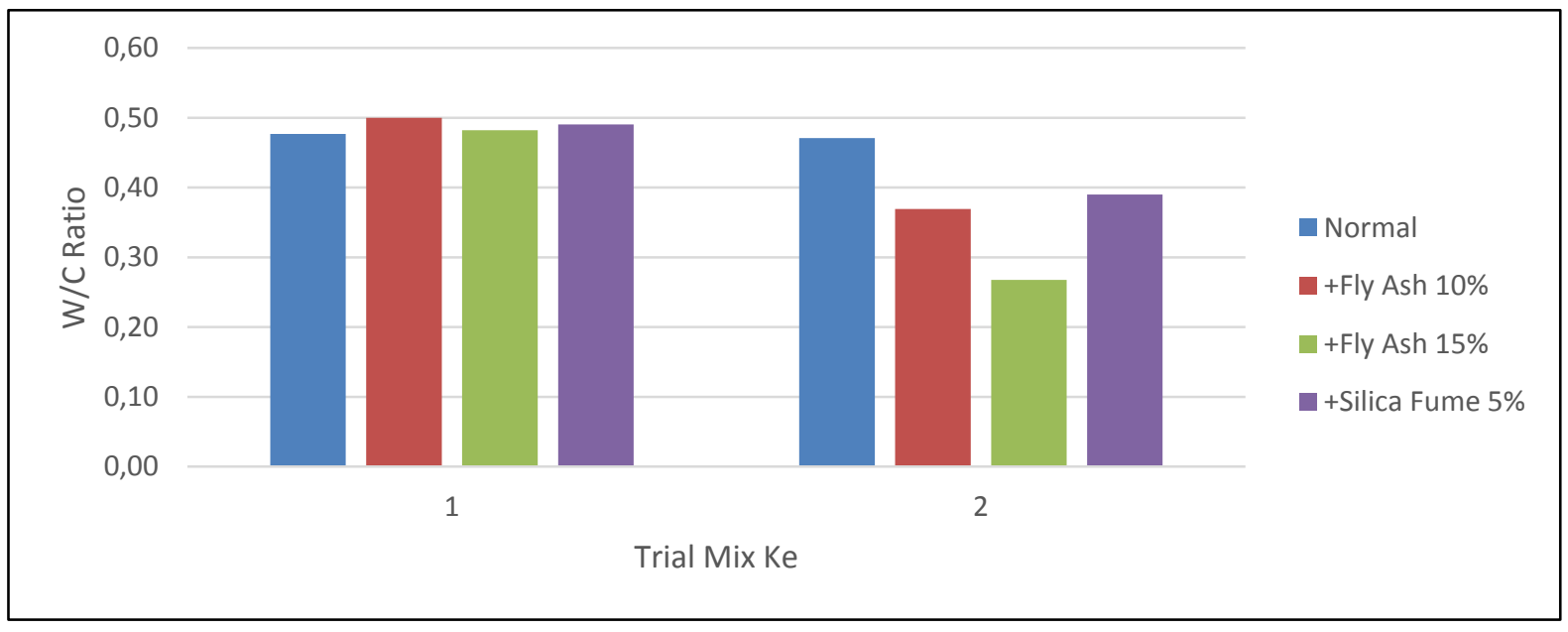

Gambar 2. Nilai Rasio Air Semen

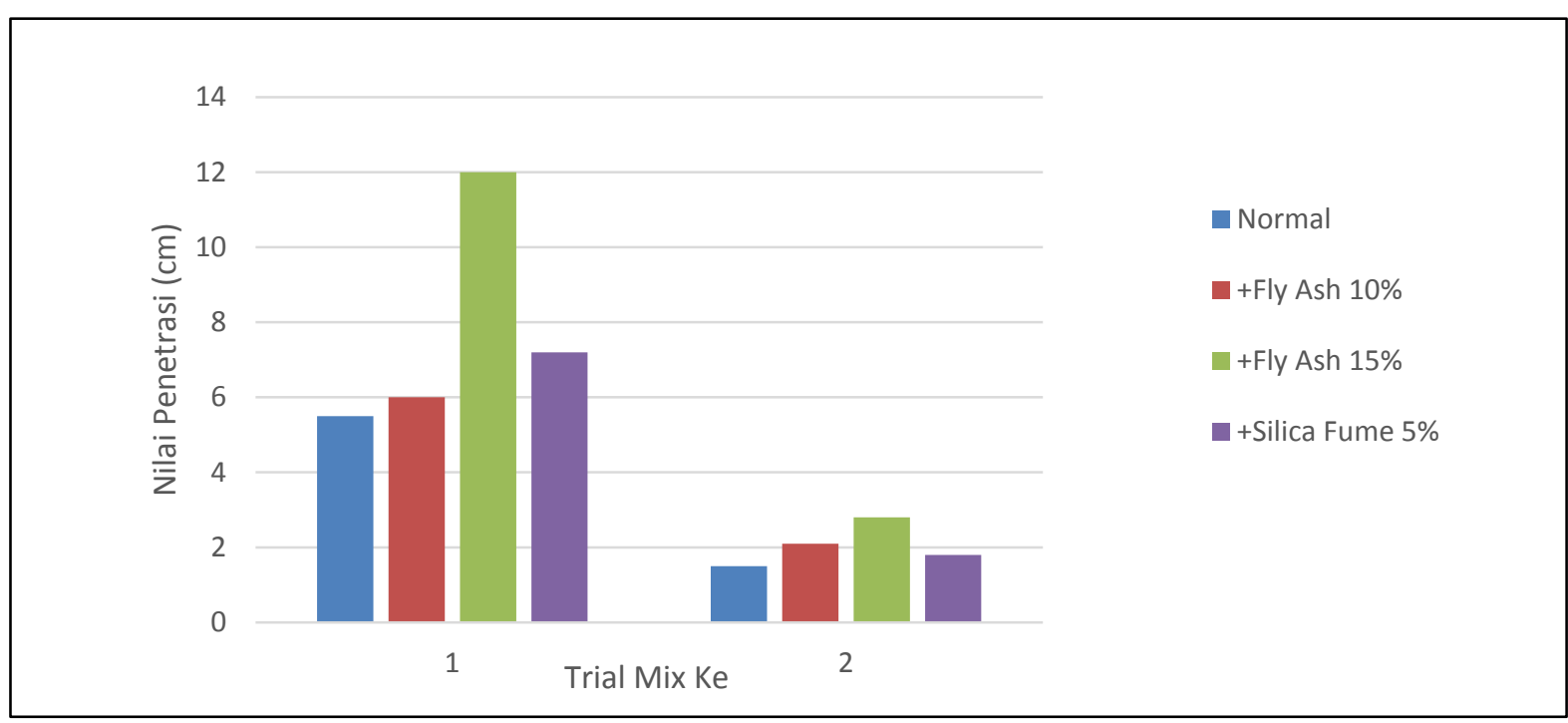

Gambar 3. Nilai Penetrasi Air 


\section{KESIMPULAN}

Perubahan jenis aditif dari tipe $\mathrm{F}$ ke $\mathrm{D}$ campuran beton efektif memperpanjang waktu pengerasan beton, sehingga memudahkan proses pengecoran dalam volume yang besar. Rata-rata waktu setting time bertambah 1-2 jam untuk beton dengan fly ash, dan lebih lama lagi untuk beton dengan silica fume.

Pada trial 1, jumlah air pada beton dengan fly ash atau silica fume bertambah, hal ini untuk menjaga konsistensi kelecakan campuran di lapangan agar tetap memenuhi nilai slump rencana $(10 \pm 2 \mathrm{~cm})$. Pada trial 2, jumlah air pada beton dengan fly ash atau silica fume diturunkan terhadap acuan, sehingga perbandingan air terhadap semen menjadi lebih kecil. Walaupun demikian, pengaruh aditif tipe D dan G cukup efektif dalam menjaga kelecakan campuran dengan fly ash atau silica fume agar mudah dialirkan.

Penambahan fly ash hingga 10\% memberikan nilai kuat tekan yang paling optimum. Tetapi penambahan fly ash atau silica fume belum memberikan pengaruh terhadap sifat kedap air yang lebih baik dibandingkan beton normalnya.

Penggunaan admixtures berkisar pada 1$1,42 \%$ berat semen. Tipe $F$ berfungsi sebagai plasticizer, sedangkan tipe D menambah fungsi retarding pada campuran beton.

\section{UCAPAN TERIMA KASIH}

Penulis mengucapkan terimakasih dan penghargaan sebesar-besarnya kepada:

- Rekan-rekan laboratorium beton atas semua bantuan dan saran selama proses penelitian ini berlangsung.

- PT. Petrokimia Gresik, PT. AJG, atas kesediaannya untuk mendanai kegiatan penelitian ini hingga dapat berlangsung lancar dan sesuai rencana.

\section{DAFTAR PUSTAKA}

[1] Uygunoglu, Tayfun, Topcu, Gencel, Osman, Brostow, Witold, 2012 ,"The Effect of Fly Ash Content and Types of Aggregates on the Properties of Prefabricated Concrete Interlocking Blocks (PCIBs)", Journal of Construction and Building Materials 30, hal 180-187, Elsevier.
[2] Chousidis, Rakanta, Ioannou, Batis, 2015, "Mechanical Properties and Durability Performance of Reinforced Concrete Containing Fly Ash", Journal of Construction and Building Materials 101 , hal 810-817, Elsevier.

[3] Marthong, Agrawal, 2012, "Effect of Fly Ash Additive on Concrete Properties", International Journal of Engineering Research and Applications (IJERA), Vol. 2 Issue 4, July-August 2012, hal 1986-1991, ISSN : 2248-9622.

[4] Mohamed, Heba, 2011, "Effect of Fly Ash and Silica Fume on Compressive Strength of Self Compacting Concrete under Different curing conditions", Ain Shams Engineering Journal, hal 79-86.

[5] Laboratorium Beton dan Bahan Bangunan, "Laporan Hasil Penelitian \& Pengujian a.n PT. Petrokimia Gresik - Proyek UPRATING - Gunung Sari”, Balai Besar Bahan dan Barang Teknik, 2014-2015.

[6] Alexander, Mark, Mindess, Sidney, 2005 “Aggregates In Concrete”, Taylor \& Francis Group, New York.

[7] Neville, A. M, Brooks, J.J, 1987, Concrete Technology, Second Edition, Prentice Hall, Pearson Education Limited, England,.

[8] Federation Internationale de la Precontrainte (FPI Commision on Concrete), 1988, Condensed Silica Fume In Concrete, Thomas Telford Ltd, London.

[9] Comite Euro-International Du Beton (CEB), 1989, Durable Concrete Structures-Design Guide, Second Edition, Thomas Telford Services Ltd, London.

[10] Mehta, Kumar P, Monteiro, Paulo, 2006, Concrete Microstructure, Properties and Materials, Third Edition, The McGrawHill Companies, Inc, USA.

[11] ACI Committe 363, 2009, State of the Art Report on High-Strength Concrete, ACI 363R-92, Manual of Concrete Practices 2009, USA. 
Jurnal Teknologi Bahan dan Barang Teknik Vol. 5, No.1, Juni 2015 :21-28 